\title{
Towards an estimation of sub-sea-ice platelet-layer volume with multi-frequency electromagnetic induction sounding
}

\author{
Priska A. HUNKELER, ${ }^{1}$ Stefan HENDRICKS, ${ }^{1}$ Mario HOPPMANN, ${ }^{1}$ Stephan PAUL, ${ }^{2}$ \\ Rüdiger GERDES ${ }^{1}$
}

\author{
${ }^{1}$ Alfred-Wegener-Institut Helmholtz-Zentrum für Polar- und Meeresforschung, Bremerhaven, Germany \\ E-mail: priska.hunkeler@awi.de \\ ${ }^{2}$ Environmental Meteorology, University of Trier, Trier, Germany
}

\begin{abstract}
Ice-platelet clusters modify the heat and mass balance of sea ice near Antarctic ice shelves and provide a unique habitat for ice-associated organisms. The amount and distribution of these ice crystals below the solid sea ice provide insight into melt rates and circulation regimes in the ice-shelf cavities, which are difficult to observe directly. However, little is known about the circum-Antarctic volume of the sub-sea-ice platelet layer, because observations have mostly been limited to point measurements. In this study, we present a new application of multi-frequency electromagnetic (EM) induction sounding to quantify platelet-layer properties. Combining in situ data with the theoretical response yields a bulk platelet-layer conductivity of $1154 \pm 271 \mathrm{mS} \mathrm{m}^{-1}$ and ice-volume fractions of 0.29-0.43. Calibration routines and uncertainties are discussed in detail to facilitate future studies. Our results suggest that multi-frequency EM induction sounding is a promising method to efficiently map platelet-layer volume on a larger scale than has previously been feasible.
\end{abstract}

KEYWORDS: basal melt, sea ice, sea-ice/ice-shelf interactions

\section{INTRODUCTION}

The Antarctic coastline is fringed by ice shelves, floating extensions of continental ice sheets (Le Brocq and others, 2010). Basal melt of ice shelves leads to the formation of water masses that are fresher and less dense than the surrounding ocean body (Mahoney and others, 2011). As the sea-water freezing point depends on pressure (Foldvik and Kvinge, 1974), the water becomes supercooled when the less dense plume rises. Ice platelets nucleate in the supercooled water, but the process of ice formation varies (Smith and others, 2001). Near the Ekström Ice Shelf in the eastern Weddell Sea, large amounts of ice platelets rise from the cavity below the ice shelf and accumulate underneath the sea ice (Eicken and Lange, 1989; Hoppmann and others, 2015). In McMurdo Sound, near the Ross Ice Shelf, platelet growth is often associated with in situ formation of ice platelets directly underneath the sea ice (Smith and others, 2001) or is interpreted as a combination of the two processes (Jeffries and others, 1993; Dempsey and others, 2010).

The resulting sub-sea-ice platelet layer, hereafter referred to as the platelet layer, may contribute significantly to the heat and mass balance of adjacent sea ice (Eicken and Lange, 1989) and represents a unique ice habitat (Arrigo and others, 1993). The additional buoyancy modifies the sea-ice freeboard, influencing satellite remote sensing near coastal areas in Antarctica (Rack and others, 2013; Price and others, 2014). Furthermore, the platelet layer is a direct indicator of ocean/ice-shelf interaction, and the amount of basal ice-shelf melt might be reflected in the volume of ice platelets found below landfast sea ice (Hoppmann and others, 2015), a region much more accessible than the cavities below ice shelves.

The total volume of ice platelets below the sea ice is a product of the layer thickness, the area and the ice-volume fraction. The platelet layer is up to several meters thick, usually determined with a thickness gauge, and the horizontal extent is given by point measurements. Previous investigations of ice-volume fractions in McMurdo Sound used estimates from core holes, ice-temperature profiles and horizontal thin sections. Results ranged from 0.2 to $>0.5$, while a recent study found an ice-volume fraction of $0.25 \pm 0.06$ using heat-flux calculations (Gough and others, 2012). At Atka Bay, Günther and Dieckmann (1999) calculated a value of 0.46 , based on consideration of seaice isostasy. Kipfstuhl (1991) and Hoppmann and others (2015) compared their sea-ice thickness observations to a localized growth model and estimated ice-volume fractions of 0.2 and $0.25 \pm 0.1$, respectively.

One physical parameter which depends on the icevolume fraction of the platelet layer is the electrical conductivity. Differences in conductivity are fundamental for sea-ice thickness retrieval with electromagnetic (EM) induction sounding, a common method typically applied with airborne (Haas and others, 2009) or ground-based devices (Kovacs and Morey, 1991; Haas and others, 1997; Haas, 1998; Reid and others, 2003). In general, a single frequency in the range $3000-10000 \mathrm{~Hz}$ is used to estimate the distance of the sensor to the ice/water interface. The method is based on the assumption that sea ice can be described as a single level layer with negligible electrical conductivity $\left(<100 \mathrm{mS} \mathrm{m}^{-1}\right.$; e.g. Reid and others, 2006) compared to sea water (e.g. $2690 \mathrm{mS} \mathrm{m}^{-1}$ in the winter Weddell Sea). This is a reasonable assumption for most offshore sea ice, but in the presence of a porous platelet layer it becomes invalid. In this case, a single-layer assumption will lead to either an overestimation of the solid sea-ice thickness (Rack and others, 2013) or an underestimation of total (solid ice + platelet layer) thickness with no possibility to resolve both layers. Single-frequency systems are sensitive to the thickness and the electrical bulk conductivity of the 


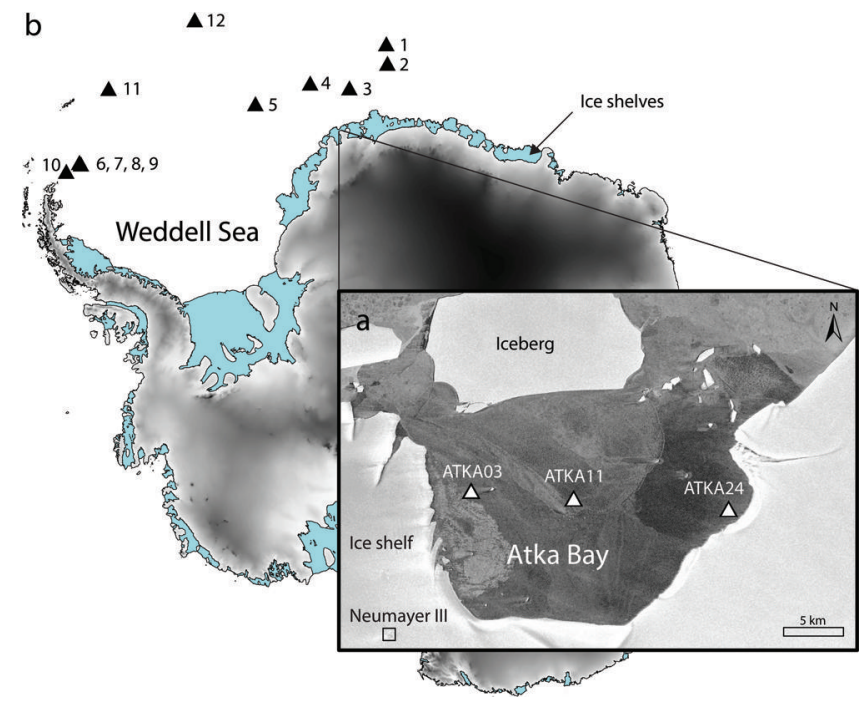

Fig. 1. Map of sea-ice study sites. (a) Enlarged map of Atka Bay, showing the survey sites with an underlying platelet layer (white triangles). Background: TerraSAR-X image from 15 November 2012, provided by the German Aerospace Center (DLR). (b) Calibration sites in the Weddell Sea without a platelet layer (black triangles). Blue areas indicate the locations of ice shelves (Fretwell and others, 2013; Bedmap2).

platelet layer, but do not provide enough observational constraints for an unambiguous resolution of layer thicknesses and conductivities. Therefore, those systems are not able to resolve multiple sea-ice layers with different electrical parameters. In exploration geophysics, it is therefore common to resolve a multilayered subsurface structure using either multiple frequencies, several transmitter/receiver configurations, or a combination of the two.

The aim of this study is to lay the foundations for rapid estimation of large-scale platelet-layer volumes, without the need for time-consuming sea-ice drilling experiments. We focus here on the analysis of multi-frequency EM induction sounding data at platelet-free calibration sites with known sea-ice thickness to assess calibration coefficients and data uncertainties for the individual instrumental frequencies. We apply calibration coefficients and uncertainties to a more complex situation with a platelet layer, to derive limitations for the parameterization of the platelet-layer conductivity and to investigate its relationship to ice-volume fraction.

\section{METHOD}

We used a commercial EM induction sensor (GEM-2, Geophex Ltd) for multi-frequency soundings on sea ice with an underlying platelet layer at several survey sites in Atka Bay. An estimation of instrumental uncertainties requires knowledge of the subsurface structure. At Atka Bay, these requirements were not fulfilled since the electrical bulk conductivity of the platelet layer is unknown and its estimation is a major goal of this study. Therefore, two additional datasets over simpler geophysical calibration targets were acquired to calculate the calibration coefficients and the uncertainties of the measurements. These calibrations were conducted over level sea ice in the central Weddell Sea (no platelet layer) and over the North Sea in Germany, where no sea ice was present (sea water only). Figure 1 shows the sea-ice survey and calibration sites.

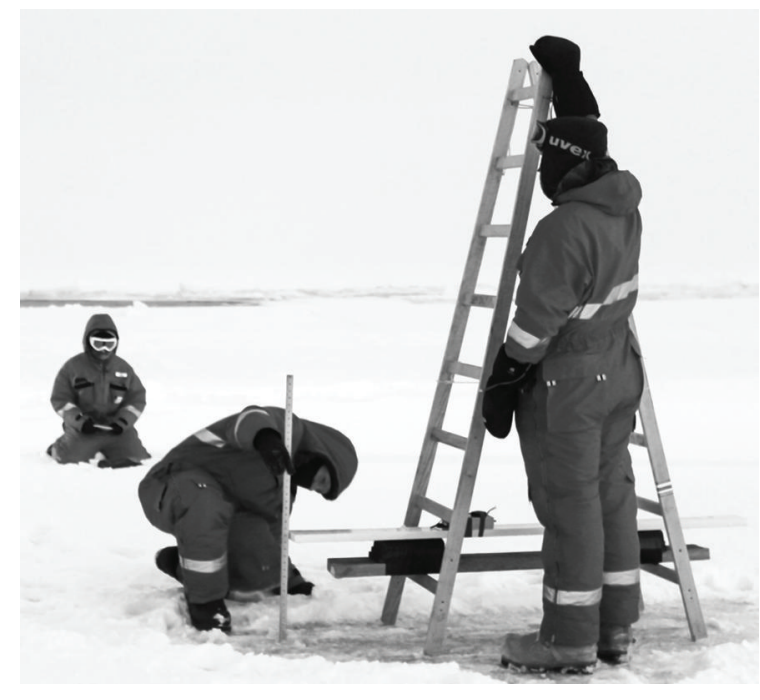

Fig. 2. Multi-frequency EM induction sounding data are recorded with the GEM-2 at different heights above sea ice. The signal directly depends on the distances to the conductive layers. Photograph by Sandra Schwegmann, 24 June 2013.

\section{Multi-frequency EM sounding}

The GEM-2 instrument (Fig. 2) is a ground-based induction sensor with promising specifications for multilayer sea-ice thickness retrieval. It can be used either in horizontal or vertical coplanar mode with a transmitter/receiver coil spacing of $1.66 \mathrm{~m}$. The coil spacing is a critical parameter, since, together with the chosen frequency, it limits the sounding depth. Although the coil spacing of the GEM-2 is small compared with the much used single-frequency Geonics EM-31 (3.67 m), it was considered to be sufficient for our purposes. The GEM-2 instrument can be operated simultaneously with up to five frequencies in a range 330$96000 \mathrm{~Hz}$. For calibration measurements in the Weddell and North Seas we used frequencies of 1530, 5310, 18330 , 63030 and $93090 \mathrm{~Hz}$. At Atka Bay we used slightly different frequencies $(450-93030 \mathrm{~Hz})$ at a sampling rate of $10 \mathrm{~Hz}$.

During operation, a primary EM field is generated by the transmitter coil of the EM instrument. The primary field induces a secondary magnetic field in all nearby conductive layers. The receiver coil measures the superimposed signal of all resulting magnetic fields. The EM response is defined as the relative secondary field, which is the secondary field divided by the primary field. It can be expressed as a complex number with the in-phase, I (real part), and the quadrature, $Q$ (imaginary part). In-phase and quadrature are dimensionless and are recorded in parts per million (ppm). An alternative representation is given by the amplitude, Amp, and phase, $\varphi$, where $\varphi=\arctan (Q / I)$ and Amp $=\sqrt{1^{2}+Q^{2}}$.

In practice, the primary field is often suppressed at the receiver coil to measure the minor secondary field at sufficient resolution. This is realized in the GEM-2 with a bucking coil, which is connected in series with the receiver coil, but has the opposite polarity (Won and others, 2003). The bucking coil has a defined area, number of turns and distance to the transmitter $(1.035 \mathrm{~m})$ to cancel the primary field at the receiver location with an equal current.

According to Frischknecht and others (1991), three types of systematic errors exist in in-phase and quadrature 
Table 1. Summary of GEM-2 datasets at Atka Bay. Date format is day/month. IT: measured sea-ice thickness (snow was removed); PLT: measured platelet-layer thickness; F: measured freeboard; T: air temperature measured at Neumayer III station; $\sigma_{\mathrm{i}}$ : estimated sea-ice conductivity; $\sigma_{\mathrm{pl}}$ : estimated platelet-layer conductivity

\begin{tabular}{|c|c|c|c|c|c|c|c|c|}
\hline Site & Date (2012) & $\begin{array}{l}\text { IT } \\
\mathrm{m}\end{array}$ & $\begin{array}{c}\text { PLT } \\
\mathrm{m}\end{array}$ & $\begin{array}{l}\mathrm{F} \\
\mathrm{m}\end{array}$ & $\begin{array}{l}{ }^{\mathrm{T}} \\
{ }^{\circ} \mathrm{C}\end{array}$ & $\begin{array}{c}\sigma_{\mathrm{i}} \\
\mathrm{mS} \mathrm{m}^{-1}\end{array}$ & $\begin{array}{c}\sigma_{\mathrm{pl}} \\
\mathrm{mS} \mathrm{m}^{-1}\end{array}$ & $\begin{array}{c}\text { Frequencies } \\
\qquad \mathrm{Hz}\end{array}$ \\
\hline ATKA11 & $21 / 11$ & 0.67 & 1.17 & -0.03 & -1.0 & 200 & 1225 & $475,1525,5325,18325,63025$ \\
\hline ATKA11 & $26 / 11(1)$ & 0.68 & 1.23 & -0.01 & -4.2 & 200 & 1125 & 5310, $18330,63030,93090$ \\
\hline ATKA24 & $26 / 11(2)$ & 1.89 & 2.24 & 0.15 & -4.6 & 40 & 1340 & $5310,18330,63030,93090$ \\
\hline ATKA11 & $1 / 12(1)$ & 0.70 & 1.43 & 0.01 & -1.5 & 200 & 1017 & $450,1530,5310,18330,63030$ \\
\hline ATKA11 & $1 / 12(2)$ & 0.70 & 1.43 & 0.01 & -1.5 & 200 & 1075 & 5310, 18330, 63030,93090 \\
\hline ATKA03 & $27 / 12(1)$ & 2.69 & 4.21 & 0.33 & -0.9 & 40 & - & 1530, 5310, 18330, 63030, 93090 \\
\hline ATKA11 & $27 / 12(2)$ & 0.79 & 1.11 & 0.07 & -1.2 & 200 & 1143 & 1530, 5310, 18330, 63030,93090 \\
\hline
\end{tabular}

recordings, due to improper adjustment and calibration of the sensor: (1) zero-level offsets, $I_{\mathrm{c}}$ and $Q_{\mathrm{c}}$, (2) scaling coefficients, $A$, and (3) phase-mixing coefficients, $P_{\mathrm{c}}$, have to be applied to the measured in-phase and quadrature components, $I_{\mathrm{m}}$ and $Q_{\mathrm{m}}$. The corrected in-phase, $I$, and quadrature, $Q$, are calculated as

$$
I=A\left[\left(I_{\mathrm{m}}+I_{\mathrm{c}}\right) \cos \left(P_{\mathrm{c}}\right)-\left(Q_{\mathrm{m}}+Q_{\mathrm{c}}\right) \sin \left(P_{\mathrm{c}}\right)\right]
$$

and

$$
Q=A\left[\left(Q_{\mathrm{m}}+Q_{\mathrm{c}}\right) \cos \left(P_{\mathrm{c}}\right)+\left(I_{\mathrm{m}}+I_{\mathrm{c}}\right) \sin \left(P_{\mathrm{c}}\right)\right] .
$$

A similar approach has been presented by Deszcz-Pan and others (1998), Reid and Bishop (2004), Brodie and Sambridge (2006) and Minsley and others (2012). Because of systematic errors in our instrument, we corrected our data according to Eqns (1) and (2) to get reliable results.

\section{Bucking coil bias}

We compared field data to numerical one-dimensional forward models (Anderson, 1979) to obtain the calibration coefficients at specific calibration sites. Model parameters were the EM frequency and the coil spacing and orientation, as well as the thickness and conductivity of multiple layers.

We found a significant bias between the actual GEM-2 response and the forward models at all sites and all frequencies. This deviation could not be explained with either realistic calibration coefficients, or with the layer conductivities at the calibration sites. We finally found that the bucking coil picked up, in addition to the primary field, a signal from the subsurface (secondary field), which could not be described with a constant factor, as described in the literature and performed during the internal instrumental processing. To account for the secondary field measured by the bucking coil, we implemented the bucking coil in our forward models as a second receiver and subtracted the result from the receiver response. By doing so, we achieved good agreement between data and forward models with realistic calibration coefficients.

\section{Relation between electrical conductivity and porosity}

Archie's law relates the bulk electrical conductivity, $\sigma$, of a porous layer to the porosity, $\Phi$, the brine conductivity, $\sigma_{\mathrm{b}}$, and the cementation factor, $m$ (Archie, 1942):

$$
\sigma=\sigma_{\mathrm{b}}(\Phi)^{m} \text {. }
$$

We used this law to convert (1) brine conductivity and brine volume of sea ice to bulk conductivity of the solid sea-ice layer and (2) bulk conductivity of the platelet layer to the actual ice-volume fraction. The empirical factor, $m$, depends, to a large extent, on the material grain shape and pore geometry (Salem and Chilingarian, 1999). Previous studies have often used a value of 1.75 for solid sea ice, and a range 1.55-2.2 is reported in the literature (Reid and others, 2006). Because of the different structure of the unconsolidated platelet layer, with higher connectivity and brine volume than solid sea ice, the cementation factor of solid sea ice might not be applicable to the platelet layer. We therefore tested a broad range of cementation factors from 1.5 to 2.5, values which are usually used for saturated sandstones (Glover and others, 1997). These structures are more likely to describe the connected pores of the platelet layer.

\section{Field data}

\section{Atka Bay}

We investigated properties of the platelet layer at Atka Bay at three sites between November 2012 and January 2013, operating from the German research station Neumayer III. The sites ATKA03, ATKA11 and ATKA24 (Fig. 1; Table 1) represent different fast-ice regimes. At ATKA11, where we repeated EM data acquisition five times, sea ice was $\sim 4$ months old, formed after a breakout in August 2012. Consequently, ATKA11 showed thinner sea ice than all the other sites. We found older first-year sea ice at ATKA24 and thicker rafted sea ice at ATKA03. A detailed description of the sea-ice conditions is given by Hoppmann and others (2015). At each site, we removed the snow and acquired multi-frequency EM data in $0.1 \mathrm{~m}$ steps in sensor altitude from the sea-ice surface to a maximum height of $2 \mathrm{~m}$ above the sea ice (Fig. 2).

After the EM sounding, we measured the freeboard, $F$, the sea-ice thickness, IT, and the platelet-layer thickness, PLT, with a modified thickness gauge through $0.05 \mathrm{~m}$ drillholes (Table 1). Individual ice platelets up to $0.1 \mathrm{~m}$ in diameter were observed. Manual sea-ice thickness measurements yielded an uncertainty of $<0.1 \mathrm{~m}$ for solid sea ice. But we could only determine the platelet-layer thickness with an accuracy of $\sim 0.3 \mathrm{~m}$, as verified by an underwater camera (Hoppmann and others, 2015). The platelet layer often consisted of internal dense layers, and in the vicinity of sea water the platelet layer was generally looser than in the middle of the layer. Surprisingly, we often found a less dense layer next to the solid sea ice. For our further calculations, however, we assumed a homogeneous platelet layer.

To determine conductivities of the water column and the interstitial platelet-layer water, we used a conductivitytemperature-depth (CTD) probe (CTD75M, Sea \& Sun Technology $\mathrm{GmbH}$ ) to perform in total 22 down- and 
Table 2. Summary of Weddell Sea and North Sea calibrations operated with frequencies 1530, 5310, 18330, 63030 and $93090 \mathrm{~Hz}$. Date format is day/month. IT: measured sea-ice thickness (snow was removed); $\mathrm{F}$ : measured freeboard; $\mathrm{T}$ : air temperature measured by Polarstern; $\sigma_{\mathrm{i}}$ : estimated sea-ice conductivity; $\sigma_{\mathrm{w}}$ : sea-water conductivity measured by Polarstern (daily average, Weddell Sea data) and by a handheld instrument (North Sea data). Note the low sea-water conductivity in the North Sea due to the inflow of fresh water (site 13)

\begin{tabular}{|c|c|c|c|c|c|c|}
\hline Site & Date (2013) & $\begin{array}{l}\text { IT } \\
\mathrm{m}\end{array}$ & $\begin{array}{l}\mathrm{F} \\
\mathrm{m}\end{array}$ & $\begin{array}{c}\mathrm{T} \\
{ }^{\circ} \mathrm{C}\end{array}$ & $\begin{array}{c}\sigma_{\mathrm{i}} \\
\mathrm{mS} \mathrm{m}^{-1}\end{array}$ & $\begin{array}{c}\sigma_{\mathrm{w}} \\
\mathrm{mS} \mathrm{m}^{-1}\end{array}$ \\
\hline 1 & $20 / 6$ & 0.53 & 0.05 & -21 & 80 & 2708 \\
\hline 2 & $21 / 6$ & 0.54 & 0.04 & -19 & 80 & 2707 \\
\hline 3 & $3 / 7$ & 0.60 & $-0.20^{*}$ & -28 & 80 & 2698 \\
\hline 4 & $8 / 7$ & 0.58 & 0.01 & -13 & 50 & 2708 \\
\hline 5 & $15 / 7$ & 0.58 & - & -3 & 10 & 2706 \\
\hline 6 & $26 / 7$ & 3.44 & - & -20 & 5 & 2712 \\
\hline 7 & $1 / 8(1)$ & $2.75^{+}$ & -0.01 & -28 & 15 & 2715 \\
\hline 8 & $1 / 8(2)$ & 2.06 & -0.01 & -28 & 15 & 2715 \\
\hline 9 & $1 / 8(3)$ & 0.74 & 0.00 & -28 & 100 & 2715 \\
\hline 10 & $5 / 8$ & $4.26^{\ddagger}$ & - & -6 & 2 & 2718 \\
\hline 11 & $31 / 8$ & 0.41 & 0.00 & -14 & 0 & 2712 \\
\hline 12 & $25 / 9$ & 0.72 & 0.00 & -11 & 300 & 2686 \\
\hline 13 & $2 / 12$ & - & - & 5 & - & 1200 \\
\hline
\end{tabular}

*flooded calibration site. ${ }^{\dagger} 0.69 \mathrm{~m}$ snow included, ${ }^{\ddagger}>1 \mathrm{~m}$ snow included.

upward casts between 21 November 2012 and 7 January 2013. The instrument was operated through core holes $0.1 \mathrm{~m}$ in diameter, with a maximum depth range of $250 \mathrm{~m}$. Small ice crystals regularly blocked the conductivity cell while the instrument was operating in the platelet layer, resulting in spuriously low conductivity values. We tried to minimize this risk by repeated up- and downward movements of the instrument. As the downward casts still contained spurious data, we determined from the undisturbed upward casts an average sea-water conductivity of $2690 \mathrm{mS} \mathrm{m}^{-1}$ below the platelet layer.

To compare the electrical conductivity of the solid seaice layer with results from the GEM-2, we retrieved several sea-ice cores and measured temperature and salinity profiles at $0.1 \mathrm{~m}$ intervals. Brine volume (porosity) was calculated according to Cox and Weeks (1983) and Leppäranta and Manninen (1988). Brine conductivity, $\sigma_{b}$, was determined after Stogryn and Desargant (1985) and Reid and others (2006). The bulk conductivity of the solid sea-ice layer, $\sigma$, was then calculated using Eqn (3) and a cementation factor, $m=1.75$ (Reid and others, 2006).

\section{Weddell Sea and North Sea}

Electromagnetic calibration data from sites with no platelet layer were acquired in the central Weddell Sea at 12 sites during two winter expeditions with the German icebreaker RV Polarstern between June and September 2013 (Table 2). Sea-ice thickness was measured with a thickness gauge, and the conductivity of the sea water was obtained by the keel salinometer of RV Polarstern (IT and $\sigma_{\mathrm{w}}$ in Table 2).

On first-year sea ice the snow was removed, which made surface flooding visible at site 3 (Table 2). On multi-year sea ice, where it was not possible to remove the snow in the footprint area, we placed the GEM-2 on top of the snow and consequently included a second layer of $0 \mathrm{mS} \mathrm{m}^{-1}$ in the forward models (site 7). At site 10, we were not able to estimate the snow depth because of internal icy layers, and consequently used the same conductivity for the sea ice and the snow layer. The bulk conductivity, $\sigma$, of the solid sea ice was obtained in the same way as at Atka Bay.

An additional calibration dataset was acquired from the North Sea over mixed ocean and river inflow water at the mouth of the river Weser near Bremerhaven, Germany (last calibration in Table 2). The conductivity of the sea water was measured with a handheld conductivity meter $\left(1200 \mathrm{mS} \mathrm{m}^{-1}\right)$. Without the presence of a sea-ice layer the EM response could be modelled as an ideal homogeneous half-space.

\section{RESULTS}

Calibration coefficients and uncertainties were calculated using the calibration data from the Weddell Sea and the North Sea. Coefficients were then applied to the Atka Bay data to estimate sea-ice and platelet-layer conductivities and the ice-volume fraction of the platelet layer.

\section{GEM-2 uncertainties}

Calibration coefficients and uncertainties were obtained by manually minimizing the difference between the GEM-2 data and theoretical forward models. Figure $3 a$ and b show typical $63030 \mathrm{~Hz}$ EM responses for different heights above sea water for the Weddell Sea calibrations. For the forward model (blue dashed line) the sea-ice layer was initially assumed to be non-conductive $\left(0 \mathrm{mS} \mathrm{m}^{-1}\right)$ and a conductivity of $2700 \mathrm{mS} \mathrm{m}^{-1}$ was assigned to the sea water. The uncorrected datasets for in-phase and quadrature (Fig. 3a and b) differ significantly from each other and from the forward models. Reasons for this variability may originate from an incorrect calibration of the GEM-2 in general, the dependence of the EM response on environmental temperatures, the influence of sea-ice conductivity and variabilities of the drillhole sea-ice thickness estimations within the footprint of the instrument.

We therefore categorize the deviation from the forward models into two main parts: first, imprecise calibration of the individual frequencies as a mean offset to the forward models (systematic error); and second, the influence of environmental temperature, sea-ice conductivity and uncertainties of thickness estimations as the inter-variability between different calibrations. The first factor can be corrected by averaging the calibration coefficients for each frequency over all calibrations. The second factor describes the uncertainty of these mean calibration coefficients.

Zero-level offset coefficients, $I_{\mathrm{c} 0}$ and $Q_{\mathrm{c} 0}$ (Table 3), were measured by lifting the GEM-2 with RV Polarstern's crane and acquiring data from several meters above ground. This free-air response was obtained for $\sim 30$ min once the instrument was in temperature equilibrium. To investigate the long-term drift and the temperature dependency, these measurements were carried out multiple times. Although the crane measurements were conducted at temperatures from -24 to $-10^{\circ} \mathrm{C}$, we did not observe a strong temperature dependence of the zero-level offsets for any frequency. Once the instrument was in temperature equilibrium, the instrumental noise $\left(I_{\mathrm{n}}\right.$ and $\left.Q_{\mathrm{n}}\right)$ was determined as the standard deviation of the time series. Mean scaling, $A$, and phase-mixing coefficients, $P_{\mathrm{c}}$, were obtained at each site (Table 2 ) by manually minimizing the root-mean-square error (rmse) between inphase and quadrature data and the forward models. It was 
necessary to use different zero-level offset coefficients, $I_{\mathrm{C}}$ and $Q_{c}$, than those obtained from the free-air experiment to reach a satisfactory agreement with the forward models. These changes significantly increased the standard deviation and, thus, the uncertainty of zero-level offset coefficients of the individual frequencies. The average of all calibration coefficients, the standard deviations from individual calibration sites and the instrumental noise are summarized in Table 3. We did not use the data from thick sea ice (site 10, Table 2) to calculate these coefficients, because the signal values were low and calibration coefficients depended mainly on the estimated sea-ice conductivity.

The sea-ice conductivities, $\sigma_{\mathrm{i}}$, for the forward models were determined with the local maximum of quadrature components of frequencies 63030 and $93090 \mathrm{~Hz}$, which are assumed to be the most sensitive to sea-ice conductivity, due to their low penetration depth. This method was applied because it is almost independent of any zero-level offset, scaling and phase-mixing corrections. In Figure 3c this is shown for theoretical forward-model curves. One particular example, the calibration at flooded site 3 (Table 2), exhibits a conductivity of $1700 \mathrm{mS} \mathrm{m}^{-1}$ for the top $20 \mathrm{~cm}$ and the local maximum is shifted significantly to higher values (Fig. 3b, red). Small conductivity changes were also necessary to fit the local maximum for non-flooded calibration sites. Estimated sea-ice conductivities, $\sigma_{\mathrm{i}}$, are summarized in Table 2 .

Using Eqns (1) and (2), all calibration data were corrected with the mean coefficients, $I_{\mathrm{C}}, Q_{\mathrm{c}}, A$ and $P_{\mathrm{C}}$ (Table 3 ). The total uncertainty for the in-phase component, $\Delta l$, was calculated with the Gaussian law of error propagation according to

$$
\begin{aligned}
\Delta l^{2}= & \left(\frac{\delta I}{\delta I_{\mathrm{c}}} \sigma_{I_{\mathrm{c}}}\right)^{2}+\left(\frac{\delta I}{\delta Q_{\mathrm{c}}} \sigma_{Q_{\mathrm{c}}}\right)^{2}+\left(\frac{\delta I}{\delta A} \sigma_{A}\right)^{2} \\
& +\left(\frac{\delta I}{\delta P_{\mathrm{c}}} \sigma_{P_{\mathrm{c}}}\right)^{2}+\left(\frac{\delta I}{\delta I_{\mathrm{m}}} \sigma_{I_{\mathrm{n}}}\right)^{2}+\left(\frac{\delta I}{\delta Q_{\mathrm{m}}} \sigma_{Q_{\mathrm{n}}}\right)^{2},
\end{aligned}
$$

under the assumption that the uncertainty of the measured in-phase and quadrature signal, $I_{\mathrm{m}}$ and $Q_{\mathrm{m}}$, is described by the noise, $I_{\mathrm{n}}$ and $Q_{\mathrm{n}}$, and the uncertainty of the remaining contributions is given by the standard deviations of the calibration coefficients. The calculation for $\Delta Q$ was performed accordingly. The corrected data (dots), the respective forward models (solid curves) and the estimated uncertainties (ellipses) for in-phase and quadrature are shown for one example dataset (site 1, Table 2) in Figure 4.

Using forward models as in Figure 4 and increasing the sea-ice thickness in $0.1 \mathrm{~m}$ steps (sea ice with $100 \mathrm{mS} \mathrm{m}^{-1}$ ), over a depth of $10 \mathrm{~m}$, the calculated uncertainties exceed in $3 \mathrm{~m}$ depth the difference of two consecutive responses. This means that it is possible to resolve solid sea ice up to $3 \mathrm{~m}$ thick at an accuracy of $0.1 \mathrm{~m}$ with GEM-2 specifications and given uncertainties.

\section{Sea-ice conductivity}

The conductivity of the solid sea ice was estimated for all calibration and survey sites by aligning the measured quadrature components of the two highest frequencies $(63030$ and $93090 \mathrm{~Hz})$ to the modelled data. This procedure yielded sea-ice conductivities of $200 \mathrm{mS} \mathrm{m}^{-1}$ for thin sea ice $(<1 \mathrm{~m})$ at ATKA11 and conductivities of $40 \mathrm{mS} \mathrm{m}^{-1}$ for thicker sea ice at ATKA03 and ATKA24 (Table 1).
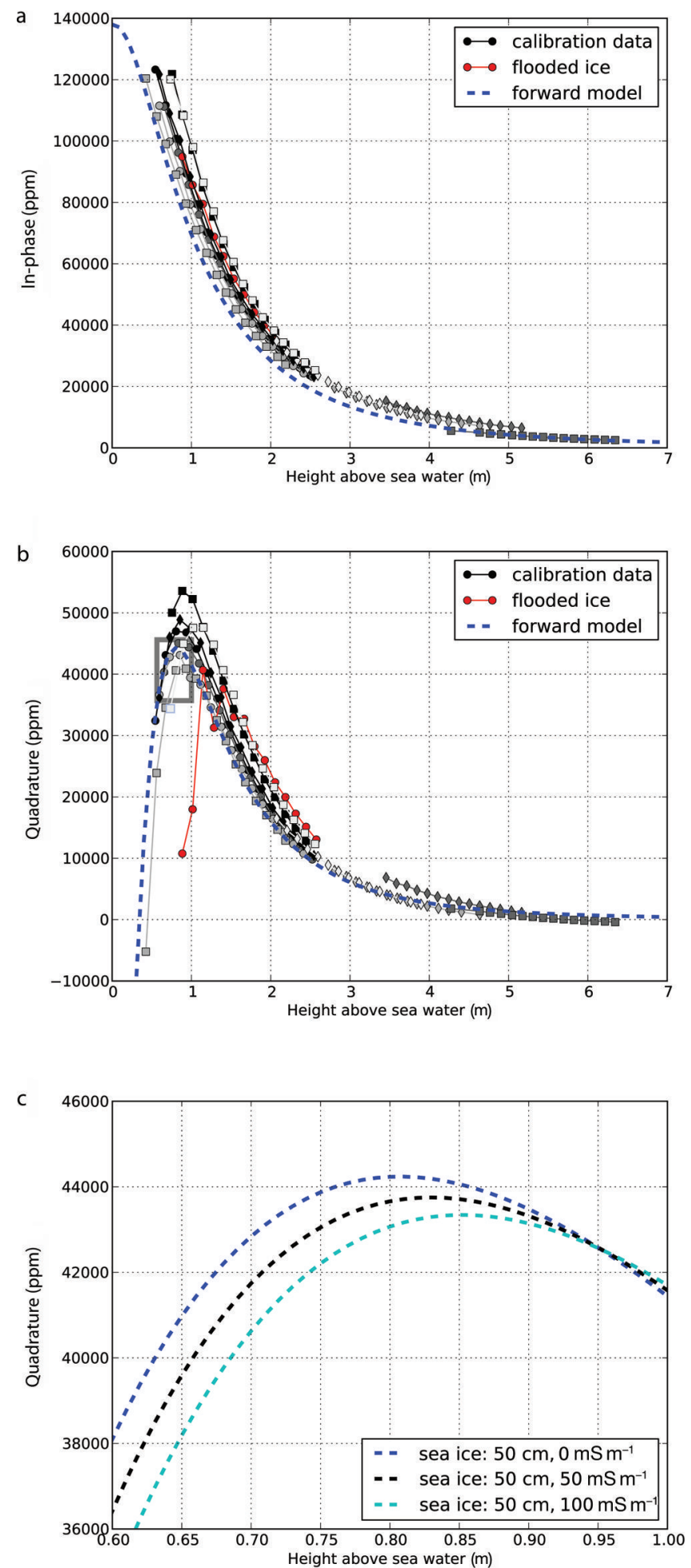

Fig. 3. Raw EM data $(63030 \mathrm{~Hz})$ for all Weddell Sea datasets. (a) Inphase, (b) quadrature and (c) enlargement of box in (b). The forward models (blue dashed curves) were calculated by assuming a homogeneous half-space of $2700 \mathrm{mS} \mathrm{m}^{-1}$ and resistive sea ice $\left(0 \mathrm{mS} \mathrm{m}^{-1}\right)$. Two additional forward models with increasing sea-ice conductivities (50 and $100 \mathrm{mS} \mathrm{m}^{-1}$ ) are shown in (c).

Brine porosity and conductivity were used to calculate the reference bulk conductivity values (Eqn (3)). The conductivities of the three ATKA11 sea-ice cores were $139 \pm 113$, $141 \pm 102$ and $149 \pm 77 \mathrm{mS} \mathrm{m}^{-1}$. These high standard deviations were mostly due to high conductivities at the ice/ water interface. If these were omitted, overall conductivities 


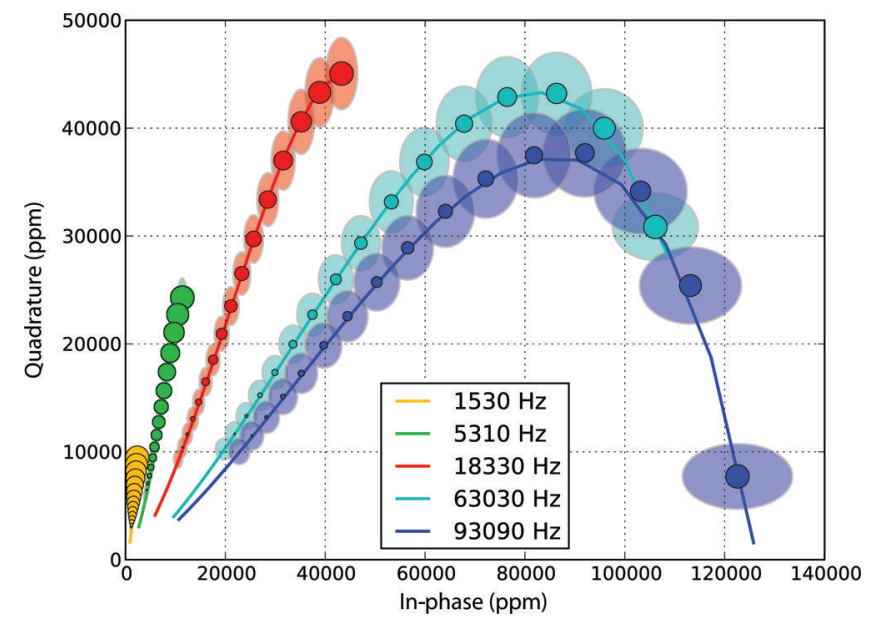

Fig. 4. Data from calibration site 1 (Table 2) with applied calibration coefficients. The instrument was lifted from zero (large dots) to $2 \mathrm{~m}$ (smaller dots) over $0.53 \mathrm{~m}$ thick sea ice with a conductivity of $80 \mathrm{mS} \mathrm{m}^{-1}$. The semi-axes of the ellipses indicate the in-phase and quadrature uncertainties. The forward models (solid curves) for $0-3 \mathrm{~m}$ are shown for the different frequencies.

reduced to $100 \pm 18,114 \pm 73$ and $127 \pm 47 \mathrm{mS} \mathrm{m}^{-1}$. Seaice cores at ATKA03 and ATKA24 yielded a sea-ice conductivity of $56 \pm 23$ and $101 \pm 35 \mathrm{mS} \mathrm{m}^{-1}$, respectively.

In the Weddell Sea, nine sea-ice cores $(<1 \mathrm{~m})$ gave sea-ice conductivities between 35 and $72 \mathrm{mS} \mathrm{m}^{-1}$, with an average of $56 \pm 14 \mathrm{mS} \mathrm{m}^{-1}$. The highest standard deviation in a single core was $55 \mathrm{mS} \mathrm{m}^{-1}$. A thicker sea-ice core of $1.77 \mathrm{~m}$ yielded a bulk sea-ice conductivity of $17 \pm 8 \mathrm{mS} \mathrm{m}^{-1}$.

In contrast, sea-ice conductivities based on forwardmodel fitting at 63030 and $93090 \mathrm{~Hz}$ ranged from 0 to $100 \mathrm{mS} \mathrm{m}^{-1}$ (with one outlier of $300 \mathrm{mS} \mathrm{m}^{-1}$ ) for thin sea ice $(<1 \mathrm{~m})$ and from 2 to $15 \mathrm{mS} \mathrm{m}^{-1}$ for thicker sea ice ( $>1 \mathrm{~m}$; Table 2). A value of $300 \mathrm{mS} \mathrm{m}^{-1}$ is a rather high conductivity for first-year sea ice, and may be explained by the presence of surface flooding or internal layers. Excluding the outlier $\left(300 \mathrm{mS} \mathrm{m}^{-1}\right)$, the conductivities from the sea-ice cores are in the same range as the conductivities from our results obtained by the GEM-2.

\section{Bulk platelet-layer conductivity}

The sea-ice conductivity at each site at Atka Bay was used as an input parameter for a series of forward models, together with the known thicknesses of solid sea ice and the platelet layer. We varied the electrical conductivity of the platelet layer using the full range of physically plausible conductivities, from a fully resistive layer $\left(0 \mathrm{mS} \mathrm{m}^{-1}\right)$ to conductive sea water $\left(2700 \mathrm{mS} \mathrm{m}^{-1}\right)$ in steps of $50 \mathrm{mS} \mathrm{m}^{-1}$. From the series of forward models (e.g. ATKA11 at $18330 \mathrm{~Hz}$; Fig. 5) we calculated the best fit between the corrected GEM-2 data (applied calibration coefficients) and the forward models, based on the local minimum of the rmse (Fig. 6). This procedure was repeated at all sites at Atka Bay for both inphase and quadrature components and for each frequency. We found that the best fit of in-phase and quadrature components did not always result in the same bulk plateletlayer conductivity. Assuming that both components should yield the same conductivity, we applied an additional phase correction at each site for every frequency. The new phasemixing coefficients were averaged and included in the uncertainty estimation $\left(P_{\mathrm{c} 2}, \sigma_{P_{\mathrm{c} 2}} ;\right.$ Table 3$)$. The averaged coefficients were again applied to both components for all frequencies at all sites, except at ATKA03, where the signal was too insensitive to the bulk platelet-layer conductivity, due to generally low signal values on the thick sea ice. We repeated the estimation of bulk platelet-layer conductivity by finding the local minimum of the rmse and also considered the upper and lower limit of the in-phase (Fig. 6) and quadrature uncertainties.

We excluded the $450 \mathrm{~Hz}$ frequency and the in-phase component of the $1530 \mathrm{~Hz}$ channel from the analysis, due to a poor signal-to-noise ratio. We found that the quadrature component of the two highest frequencies only weakly depended on the bulk-conductivity variations of the platelet layer at most sites, and we thus excluded these from further analysis. Based on the small penetration depth of these frequencies and the typical thickness of the fast ice, this was not unexpected.

The local minima of the rmse of all processed frequencies and components were averaged by survey site (Fig. 7) and by individual frequencies (Fig. 8). For individual sites we found mean bulk platelet-layer conductivities in the range

Table 3. Calibration coefficients for all frequencies. Noise of in-phase, $I_{n}$, and quadrature, $Q_{n}$, components estimated by long time series; zero-level offset coefficients, $I_{\mathrm{c} 0}$ and $Q_{\mathrm{c} 0}$, measured with a crane away from any conductive material. Zero-level offset coefficients, $I_{\mathrm{c}}$ and $Q_{c}$, scaling coefficients, $A$, and phase-mixing coefficients, $P_{c}$, obtained by minimizing the difference between field data and forward models. $P_{\mathrm{c} 2}$ are the phase-mixing coefficients adjusted for the Atka Bay datasets. $\bar{x}$ is the arithmetic average and $\sigma$ the $1 \sigma$ standard deviation of the individual calibration coefficients

\begin{tabular}{|c|c|c|c|c|c|c|c|c|c|c|}
\hline Frequency & $\bar{x} / \sigma$ & $I_{\mathrm{n}}$ & $Q_{\mathrm{n}}$ & $l_{\mathrm{C} 0}$ & $I_{\mathrm{C}}$ & $Q_{\mathrm{c} 0}$ & $Q_{\mathrm{c}}$ & $A$ & $P_{\mathrm{C}}$ & $P_{\mathrm{c} 2}$ \\
\hline $\mathrm{Hz}$ & & ppm & ppm & ppm & ppm & ppm & ppm & & $\circ$ & $\circ$ \\
\hline \multirow[t]{2}{*}{1530} & $\bar{x}$ & & & -200 & -45 & -190 & 118 & 0.82 & -0.07 & -1.17 \\
\hline & $\sigma$ & 138 & 137 & 256 & 138 & 25 & 137 & 0.05 & 1.51 & 3.58 \\
\hline 5310 & $\bar{x}$ & & & -799 & -405 & 77 & 328 & 0.82 & 0.65 & -1.10 \\
\hline \multirow[t]{2}{*}{18330} & $\bar{X}$ & & & -183 & 417 & 487 & 671 & 0.83 & 0.87 & -0.14 \\
\hline & $\sigma$ & 125 & 125 & 242 & 547 & 6 & 576 & 0.06 & 0.73 & 1.28 \\
\hline \multirow[t]{2}{*}{63030} & $\bar{X}$ & & & -932 & -757 & 1331 & 1081 & 0.87 & 0.92 & 1.79 \\
\hline & $\sigma$ & 146 & 135 & 284 & 695 & 133 & 498 & 0.07 & 0.98 & 2.98 \\
\hline \multirow[t]{2}{*}{93090} & $\bar{X}$ & & & -3474 & -3420 & 240 & 39 & 0.89 & 0.27 & 4.72 \\
\hline & $\sigma$ & 204 & 193 & 352 & 683 & 460 & 685 & 0.08 & 1.35 & 4.24 \\
\hline
\end{tabular}



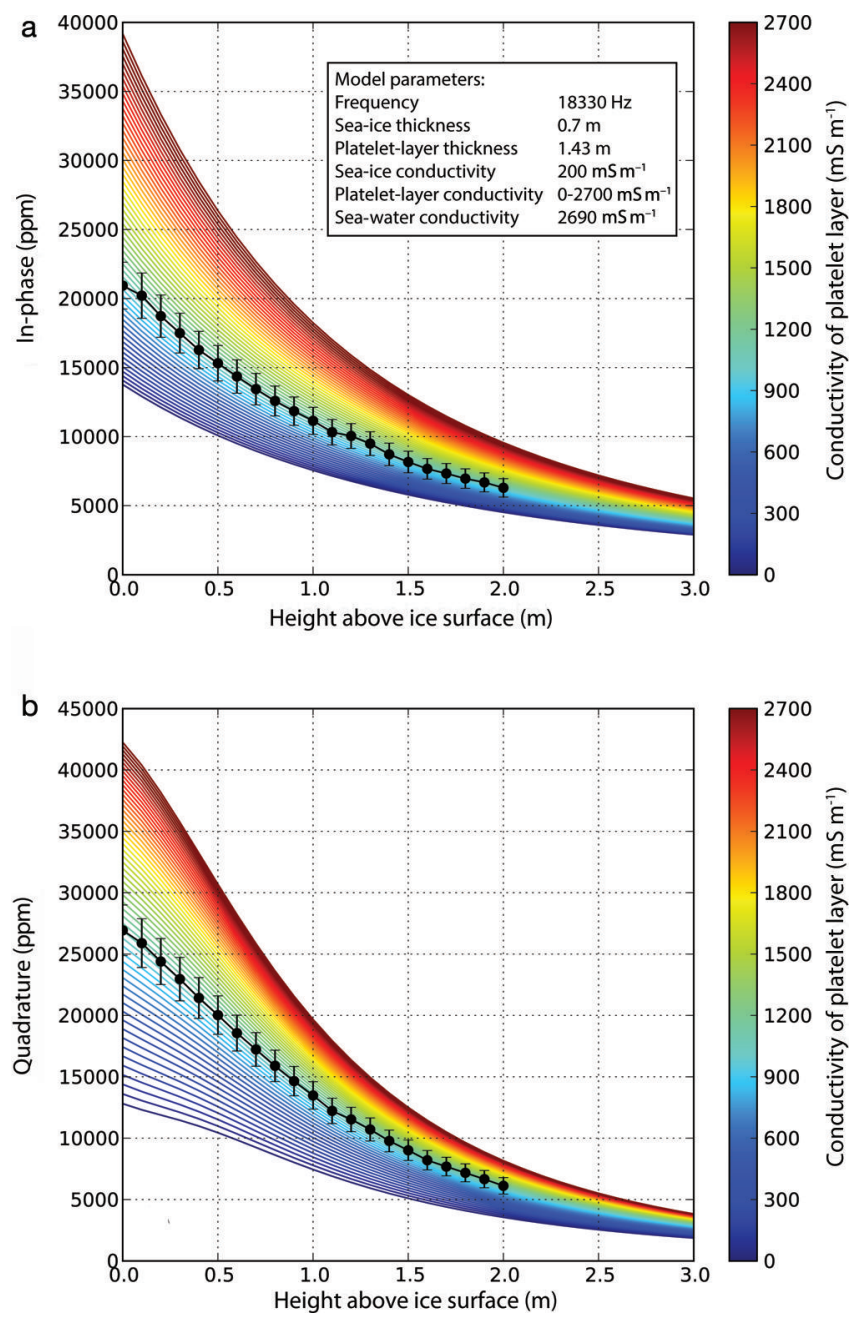

Fig. 5. Corrected dataset and corresponding uncertainties for the (a) in-phase and (b) quadrature $18330 \mathrm{~Hz}$ component at ATKA11 (1 December 2012). The forward models were calculated assuming various platelet-layer conductivities (color bar).

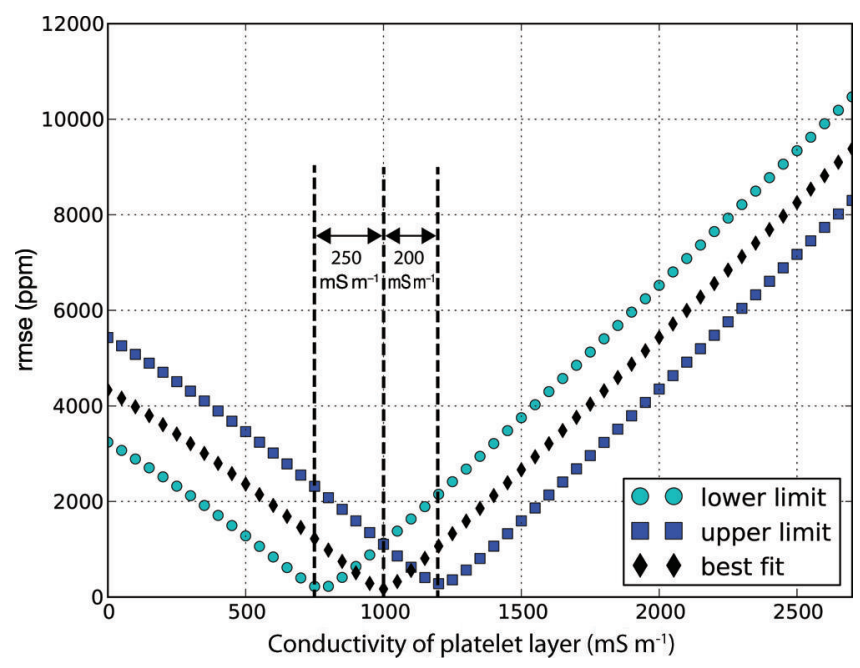

Fig. 6. Root-mean-square errors (rmse) were calculated for the inphase component (Fig. 5a) to find the smallest difference between this dataset and individual forward models. This is shown for the best fit, for the lower limit of uncertainties and for the upper limit. The bulk platelet-layer conductivity is, in this example, $1000 \mathrm{mS} \mathrm{m}^{-1}$ with a difference of $250 \mathrm{mS} \mathrm{m}^{-1}$ to the lower and $200 \mathrm{mS} \mathrm{m}^{-1}$ to the upper limit.

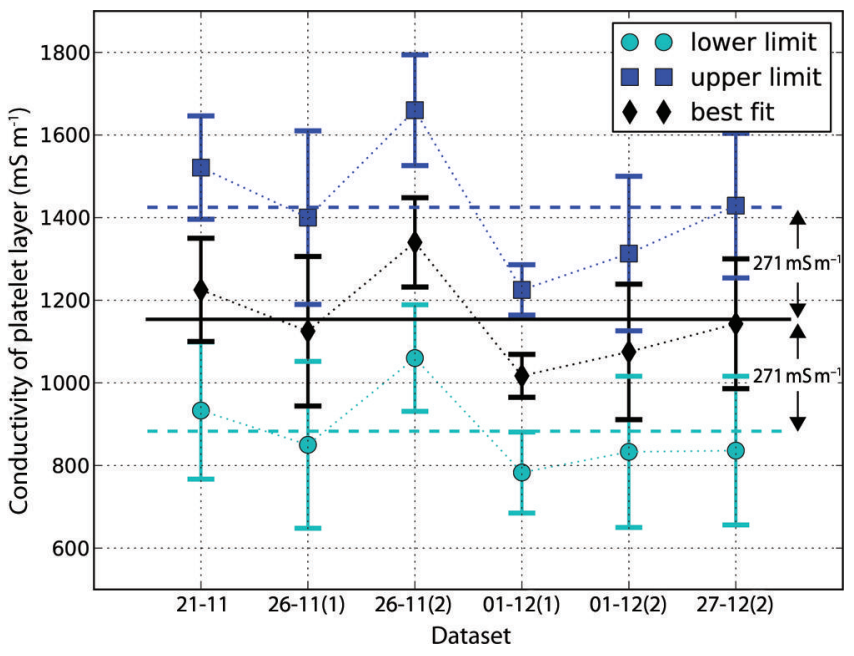

Fig. 7. Bulk platelet-layer conductivities. The results obtained using different frequencies are averaged and shown for the individual sites. The conductivities and the corresponding standard deviations are shown for the best fit, and the lower and upper limit of uncertainties. Dataset date format is day-month of 2012.

1017-1340 $\mathrm{mS} \mathrm{m}^{-1}$ (Fig. 7, best fit). The mean of these values resulted in a bulk platelet-layer conductivity of $1154 \mathrm{mS} \mathrm{m}^{-1}$ (Fig. 7, solid black line). The mean value of the lower uncertainty limit was $883 \mathrm{mS} \mathrm{m}^{-1}$ and of the upper uncertainty limit $1425 \mathrm{mS} \mathrm{m}^{-1}$, which resulted in an overall uncertainty of $\pm 271 \mathrm{mS} \mathrm{m}^{-1}$. We observed highest bulk platelet-layer conductivity at ATKA24, the site with a thicker sea ice and platelet layer $(1.89+2.24 \mathrm{~m})$ than at ATKA11. Here we assume that an internal conductive layer was located in the platelet layer.

We observed a frequency dependence of the bulk platelet-layer conductivity (Fig. 8), where higher frequencies tended to result in higher conductivities, even though upper layers may be, in general, more consolidated. Whether the reason for this relationship is a calibration error or insufficient description of the layering by the forward models is not known.

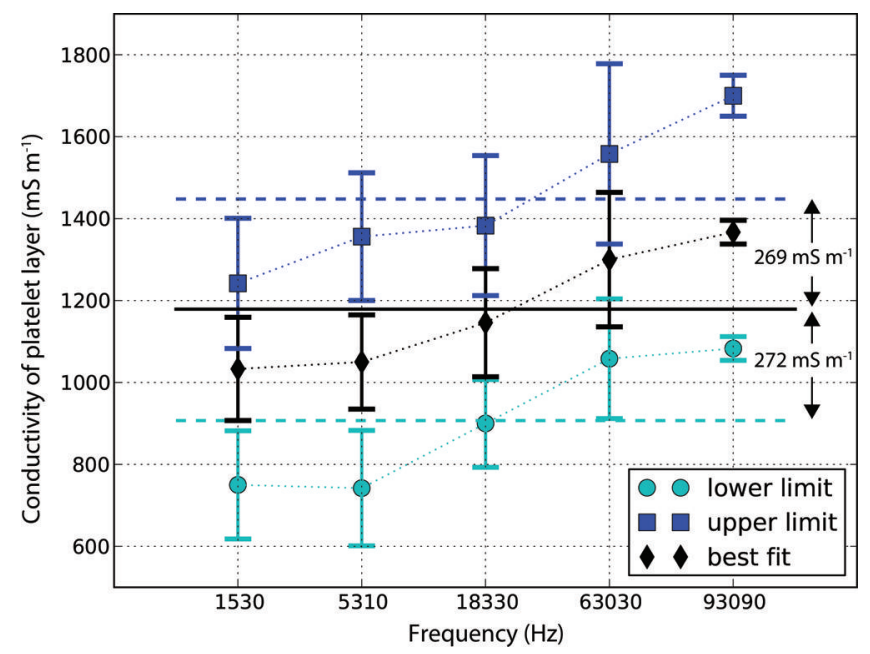

Fig. 8. Bulk platelet-layer conductivities. The results obtained at the different sites are averaged and shown for the individual frequencies. The conductivities and the corresponding standard deviations are shown for the best fit, and the lower and upper limit of uncertainties. 


\section{Ice-volume fraction of platelet layer}

The next step was to convert the layer conductivity to porosity. We used Archie's law (Eqn (3)), where the brine conductivity, $\sigma_{\mathrm{b}}$, is the conductivity of the liquid phase in the platelet layer. To a first-order approximation, $\sigma_{\mathrm{b}}$ can be described by the conductivity of the sea-water column below.

In eight down- and two upward CTD casts, the water in the platelet layer appeared to be much fresher than the sea water (1800 vs $2690 \mathrm{mS} \mathrm{m}^{-1}$ ), but we interpret these low values as an interaction between ice platelets and the conductivity sensor. We assumed cementation factors, $m$, between 1.5 and 2.5. Applying these parameters to different brine conductivities, $\sigma_{\mathrm{b}}$, and bulk platelet-layer conductivities, $\sigma$, with lower and upper limits of uncertainties, we found a range of ice-volume fractions $(1-\Phi$, where $\Phi$ is porosity; Table 4).

The resulting ice-volume fractions were in the range $0.16-0.26$ for sea-water conductivities $\sigma_{\mathrm{b}}=1800 \mathrm{mS} \mathrm{m}^{-1}$, which we considered to be spuriously low. For regular sea water of $\sigma_{\mathrm{b}}=2690 \mathrm{mS} \mathrm{m}^{-1}$ the ice-volume fractions were in the range 0.29-0.43. Accounting for the lower and upper uncertainty limits, ice-volume fractions for spuriously low brine conductivity, $\sigma_{\mathrm{b}}$, were 0.09-0.38, and for sea-water brine conductivity they were $0.22-0.52$. The ice-volume fraction was equally influenced by the choice of cementation factor, $m$, and brine conductivity, $\sigma_{\mathrm{b}}$.

\section{DISCUSSION}

We have shown that, for given thicknesses of solid sea ice and the platelet layer, it is possible to use multi-frequency EM induction soundings to resolve the bulk platelet-layer conductivity within an uncertainty range of $271 \mathrm{mS} \mathrm{m}^{-1}$. The uncertainty is mainly governed by the inter-variability between calibrations, rather than by the instrumental noise of the GEM-2. Consequently, the uncertainties of the calibration coefficients can be reduced significantly with proper calibrations. As stated above, we are able to resolve with GEM-2 data a solid sea-ice layer of $3 \mathrm{~m}$ with an accuracy of $0.1 \mathrm{~m}$, based on calculated uncertainties. Reducing the uncertainty by $50 \%$ will allow us to resolve solid sea ice of up to $4.20 \mathrm{~m}$ at an accuracy of $0.1 \mathrm{~m}$. ATKA03 with its $2.69 \mathrm{~m}$ solid sea ice and $4.21 \mathrm{~m}$ platelet layer could not be resolved by the set-up used. Theoretical calculations, however, showed that it would be possible to resolve these layers with frequencies up to $18330 \mathrm{~Hz}$ by further reducing the uncertainties.

During our first operations of the GEM-2 at Atka Bay fast ice, we tested different frequency configurations in order to evaluate its potential (Table 1). Frequencies of 1530, 5310, 18330, 63030 and $93090 \mathrm{~Hz}$ showed promising results, as the various frequencies are sensitive to different depths, while a frequency as low as $450 \mathrm{~Hz}$ was too noisy. In general, lower frequencies are more sensitive to deeper structures, and higher frequencies to the shallower sea ice. With the two highest frequencies, we obtained sea-ice conductivities similar to those from independent results of sea-ice cores. This can be very useful for other studies, especially for a non-destructive determination of sea-ice properties (e.g. Haas and others, 2008). Although first-year sea ice is generally more electrically conductive than thick sea ice, the sea-ice conductivities from forward-model fitting
Table 4. Ice-volume fractions of the platelet layer assuming different values for cementation factor, $m$, conductivities of interstitial water in the platelet layer, $\sigma_{\mathrm{b}}$, and bulk platelet-layer conductivities, $\sigma$, of the lower uncertainty limit $\left(883 \mathrm{mS} \mathrm{m}^{-1}\right)$, the best fit $\left(1154 \mathrm{mS} \mathrm{m}^{-1}\right)$ and the upper uncertainty limit $\left(1425 \mathrm{mS} \mathrm{m}^{-1}\right)$

\begin{tabular}{lcccccc}
\hline$\sigma_{\mathrm{b}}\left(\mathrm{mS} \mathrm{m}^{-1}\right):$ & 1800 & & \multicolumn{5}{c}{2690} \\
$\sigma\left(\mathrm{mS} \mathrm{m}^{-1}\right):$ & 883 & 1154 & 1425 & 883 & 1154 & 1425 \\
& & & & & & \\
\hline$m=1.5$ & 0.38 & 0.26 & 0.14 & 0.52 & 0.43 & 0.35 \\
$m=2.0$ & 0.30 & 0.20 & 0.11 & 0.43 & 0.35 & 0.27 \\
$m=2.5$ & 0.25 & 0.16 & 0.09 & 0.36 & 0.29 & 0.22 \\
\hline
\end{tabular}

at ATKA11 were with $200 \mathrm{mS} \mathrm{m}^{-1}$ unexpectedly high. At this site the freeboards were close to zero, and a slushy snow/ice interface was observed after the snow was removed, which probably influenced the GEM-2 recordings.

For further GEM-2 studies, where an absolute calibration is desired, we strongly suggest calculating calibration coefficients and uncertainties for all the individual frequencies. Nevertheless, the instrument can still be used in a traditional way for single-frequency sea-ice thickness retrievals, similar to an EM-31, where an exponential fit to calibration data at a single frequency is used to directly determine the sea-ice thickness (e.g. Haas and others, 1997). The advantages of the GEM-2 over the EM-31 are the different sounding depths, due to several frequencies, and recording of in-phase and quadrature. The two components provide independent measurements at a single frequency and thereby reduce the ambiguity of the recorded signal, which is important for the determination of the calibration coefficients. The in-phase component of the EM-31 is often at saturation, and the apparent conductivity is calculated with the quadrature component. In general, the in-phase component is more sensitive to deeper structures than the quadrature component.

Correcting the Atka Bay data with the calibration coefficients revealed that an additional phase shift had to be applied. This is possibly linked to the fundamentally different temperature regimes at the calibration sites, where the mean calibration coefficients were obtained. Slightly different frequency configurations had only a minor influence. This highlights the importance of careful calibration measurements for future field campaigns. We measured environmental temperatures during all our surveys, but could not see a strong temperature dependence of individual measurements, although the instrument was in temperature equilibrium with its surroundings.

While the uncertainty associated with the GEM-2 data mainly affects the estimation of platelet-layer conductivity, the subsequent conversion to ice-volume fraction strongly depends on physical assumptions of pore and ice-platelet shapes. For example, we assume that the pore-water is connected, which would generally indicate a low value for the cementation factor, $m$, in Archie's law (Glover, 2009). A lower value indicates spherical pores and grains (Salem and Chilingarian, 1999), but this is not the case for individual disk-shaped ice platelets within the platelet layer. Using thin sections for sea-ice cores from Atka Bay, Hoppmann and others (2015) found randomly oriented ice platelets (which agrees with recent findings of Gough and others, 2012). This factor might again result in a lower value of $m$, due to less 
angularity. However, to date, no studies exist that describe the cementation factor, $m$, for the platelet layer using independent measurements. Instead, we calculated a brine platelet-layer conductivity with a range of values, 1.5-2.5, normally observed in sandstones (Glover and others, 1997). In general, we get better agreement with results from recent studies (Gough and others, 2012; Hoppmann and others, 2015) with higher cementation factors or lower brine conductivities.

The brine conductivity, $\sigma_{\mathrm{b}}$, measured by CTD casts creates an additional uncertainty. Hoppmann and others (2015) showed that the platelet layer was already thinning when the GEM-2 surveys were conducted (November 2012-January 2013), due to the inflow of warm water masses. Hence, the brine conductivity may have decreased due to ice melt in late December. Nevertheless, these melt rates and the associated freshening do not explain the low conductivities $\left(\sim 1800 \mathrm{mS} \mathrm{m}^{-1}\right)$ recorded. Also, the bulk platelet-layer conductivity at ATKA11 on 27 December (Fig. 7) did not decrease compared with earlier calibrations.

Apart from the physical assumptions of the platelet layer and the conversion of conductivities to ice-volume fraction, we assumed the ideal case of two layers, which are level within the footprint of the sensor. We tried to compensate for this effect by measuring sea-ice thickness in the footprint range of the instrument through several drillholes. This assumption most likely does not hold for thicker sea ice and platelet layers, where sub-ice topographies or internal layers may be present more often.

With frequencies more sensitive to the solid sea-ice layer and the significant extension of the frequency range to lower values, we are confident that we can resolve both plateletlayer thickness and conductivity using a geophysical inversion scheme. The result of the inversion might be that a two-layer case is not sufficient; instead it may be necessary to have several platelet layers to explain the apparent relationship (Fig. 8) between bulk platelet-layer conductivity and frequency. However, data inversion is only possible when the bias of the bucking coil is included in inversion algorithms.

\section{CONCLUSION}

This study is a step towards sub-sea-ice platelet-layer volume estimation of Antarctic fast ice with EM induction sounding. We used the multi-frequency ground-based instrument GEM-2, operated at frequencies of $450-93090 \mathrm{~Hz}$. We compared measurements at sites of known sea-ice and platelet-layer thicknesses at Atka Bay with two-layered forward models, deriving a mean bulk platelet-layer conductivity of $1154 \pm 271 \mathrm{mS} \mathrm{m}^{-1}$. Assuming a range of cementation factors for the platelet layer, we obtained icevolume fractions of $0.29-0.43$, while values of $0.25 \pm 0.06$ and $0.25 \pm 0.1$ have recently been found by other methods (Gough and others, 2012; Hoppmann and others, 2015). Using the quadrature component of higher frequencies, 63030 and $93090 \mathrm{~Hz}$, we were able to estimate conductivities of the solid sea-ice layer. Accurate calibrations are required to reduce the uncertainties of multi-frequency EM measurements to make them useful for the determination of the platelet-layer volume. Comparisons of calibration data and forward models revealed that it is crucial to include the signal response of the bucking coil in the theoretical calculations. In general, multi-frequency soundings are superior to single-frequency soundings and may also improve sea-ice thickness retrieval over deformed and porous sea ice that has similar macroscale properties to the platelet layer in Antarctica. Our results provide elemental physical constraints for the layer conductivities and icevolume fractions. As we continue this work, we intend to conduct a joint analysis of all frequencies using a geophysical inversion to retrieve platelet-layer thickness and conductivities simultaneously. Multi-frequency EM induction sounding will enable us to survey ice-platelet volume below the Antarctic near-coastal sea ice on a much larger scale than by direct measurements through drillholes. Our method can also be applied to data from multi-frequency airborne sensors, which have recently been developed (Pfaffhuber and others, 2012).

\section{ACKNOWLEDGEMENTS}

We thank Thomas Schmidt, Meike Kühnel and Uwe Baltes for their fieldwork at Atka Bay. We thank the German Space Agency (DLR) for the TerraSAR-X image, and Christine Wesche for post-processing and calibrating the data. We are grateful to Robert Ricker, Thomas Krumpen and Martin Schiller for their fieldwork on board RV Polarstern (ANTXXIX/6 and 7) and Xenia II. We thank Jean-Louis Tison for providing the sea-ice core data from the Weddell Sea campaign, and AWI logistics for their support. This work was partly supported by the German Research Council (DFG) in the framework of the priority program Antarctic Research, with comparative investigations in Arctic ice areas by grants SPP1158, NI1092/2 and HE2740/12, the graduate school POLMAR and the Alfred-Wegener-Institut Helmholtz-Zentrum für Polar- und Meeresforschung. We are also grateful to the reviewers whose comments and suggestions improved the clarity of the manuscript.

\section{REFERENCES}

Anderson WL (1979) Numerical integration of related Hankel transforms of orders 0 and 1 by adaptive digital filtering. Geophysics, 44(7), 1287-1305 (doi: 10.1190/1.1441007)

Archie GE (1942) The electrical resistivity $\log$ as an aid in determining some reservoir characteristics. Trans. AIME, 146(99), 54-62 (doi: 10.2118/942054-G)

Arrigo KR, Robinson DH and Sullivan CW (1993) A high resolution study of the platelet ice ecosystem in McMurdo Sound, Antarctica: photosynthetic and bio-optical characteristics of a dense microalgal bloom. Mar. Ecol. Progr. Ser., 98(1-2), 173-185

Brodie R and Sambridge M (2006) A holistic approach to inversion of frequency-domain airborne EM data. Geophysics, 71(6), G301-G312 (doi: 10.1190/1.2356112)

Cox GFN and Weeks WF (1983) Equations for determining the gas and brine volumes in sea-ice samples. J. Glaciol., 29(102), 306-316

Dempsey DE, Langhorne PJ, Robinson NJ, Williams MJM, Haskell TG and Frew RD (2010) Observation and modeling of platelet ice fabric in McMurdo Sound, Antarctica. J. Geophys. Res., 115(C1), C01007 (doi: 10.1029/2008JC005264)

Deszcz-Pan M, Fitterman DV and Labson VF (1998) Reduction of inversion errors in helicopter EM data using auxiliary information. Expl. Geophys., 29(2), 142-146 (doi: 10.1071/EG998142)

Eicken $\mathrm{H}$ and Lange MA (1989) Development and properties of sea ice in the coastal regime of the southeastern Weddell Sea. J. Geophys. Res., 94(C6), 8193-8206 (doi: 10.1029/ JC094iC06p08193) 
Foldvik A and Kvinge T (1974) Conditional instability of sea water at the freezing point. Deep-Sea Res., 21(3), 169-174 (doi: 10.1016/0011-7471(74)90056-4)

Fretwell P and 59 others (2013) Bedmap2: improved ice bed, surface and thickness datasets for Antarctica. Cryosphere, 7(1), 375-393 (doi: 10.5194/tc-7-375-2013)

Frischknecht FC, Labson VF, Spies BR and Anderson WL (1991) Profiling methods using small sources. In Nabighian MN ed. Electromagnetic methods in applied geophysics, Vol. 2. (Investigations in Geophysics 3) Society of Exploration Geophysicists, Tulsa, OK, 105-270

Glover P (2009) What is the cementation exponent? A new interpretation. Lead. Edge, 28(1), 82-85 (doi: 10.1190/ 1.3064150)

Glover PWJ, Gómez JB, Meredith PG, Hayashi K, Sammonds PR and Murrell SAF (1997) Damage of saturated rocks undergoing triaxial deformation using complex electrical conductivity measurements: experimental results. Phys. Chem. Earth, 22(1-2), 57-61 (doi: 10.1016/S0079-1946(97)00078-5)

Gough AJ, Mahoney AR, Langhorne PJ, Williams MJM, Robinson NJ and Haskell TG (2012) Signatures of supercooling: McMurdo Sound platelet ice. J. Glaciol., 58(207), 38-50 (doi: 10.3189/ 2012JoG10J218)

Günther S and Dieckmann G (1999) Seasonal development of high algal biomass in snow-covered fast ice and the underlying platelet layer in Atka Bay, Antarctica. Antarct. Sci., 11(3), 305-315 (doi: 10.1017/S0954102099000395)

Haas C (1998) Evaluation of ship-based electromagnetic inductive thickness measurements of summer sea-ice in the Bellingshausen and Amundsen Seas, Antarctica. Cold Reg. Sci. Technol., 27(1), 1-16 (doi: 10.1016/S0165-232X(97)00019-0)

Haas C, Gerland S, Eicken H and Miller H (1997) Comparison of sea-ice thickness measurements under summer and winter conditions in the Arctic using a small electromagnetic induction device. Geophysics, 62(3), 749-757 (doi: 10.1190/1.1444184)

Haas C, Nicolaus M, Willmes S, Worby A and Flinspach D (2008) Sea ice and snow thickness and physical properties of an ice floe in the western Weddell Sea and their changes during spring warming. Deep-Sea Res. II, 55(8-9), 963-974 (doi: 10.1016/j. dsr2.2007.12.020)

Haas C, Lobach J, Hendricks S, Rabenstein L and Pfaffling A (2009) Helicopter-borne measurements of sea ice thickness, using a small and lightweight, digital EM system. J. Appl. Geophys., 67(3), 234-241 (doi: 10.1016/j.jappgeo.2008.05.005 )

Hoppmann $M$ and 11 others (2015) Ice platelets below Weddell Sea landfast sea ice. Ann. Glaciol., 56(69) (see paper in this issue) (doi: 10.3189/2015AoG69A678)

Jeffries MO, Weeks WF, Shaw R and Morris K (1993) Structural characteristics of congelation and platelet ice and their role in the development of Antarctic land-fast sea ice. J. Glaciol., 39(132), 223-238

Kipfstuhl J (1991) Zur Entstehung von Unterwassereis und das Wachstum und die Energiebilanz des Meereises in der Atka Bucht, Antarktis. Ber. Polarforsch/Rep. Pol. Res. 85
Kovacs A and Morey RM (1991) Sounding sea ice thickness using a portable electromagnetic induction instrument. Geophysics, 56(12), 1992-1998 (doi: 10.1190/1.1443011)

Le Brocq AM, Payne AJ and Vieli A (2010) An improved Antarctic dataset for high resolution numerical ice sheet models (ALBMAP v1). Earth Syst. Sci. Data, 2(2), 247-260 (doi: 10.5194/essdd-3195-2010)

Leppäranta M and Manninen T (1988) The brine and gas content of sea ice, with attention to low salinities and high temperatures. (Internal Rep. 88-2) Finnish Institute of Marine Research, Helsinki

Mahoney AR and 6 others (2011) The seasonal appearance of ice shelf water in coastal Antarctica and its effect on sea ice growth. J. Geophys. Res., 116(C11), C11032 (doi: 10.1029/ 2011JC007060)

Minsley BJ, Smith BD, Hammack R, Sams JI and Veloski G (2012) Calibration and filtering strategies for frequency domain electromagnetic data. J. Appl. Geophys., 80, 56-66 (doi: 10.1016/j.jappgeo.2012.01.008)

Pfaffhuber AA, Hendricks S, Hunkeler P and Kvistedal YA (2012) Introducing a new generation multi-sensor airborne system for mapping sea ice cover of polar oceans. First Break, 30(8), 83-88

Price D, Rack W, Langhorne PJ, Haas C, Leonard G and Barnsdale K (2014) The sub-ice platelet layer and its influence on freeboard to thickness conversion of Antarctic sea ice. Cryos. Discuss., 8(1), 999-1022 (doi: 10.5194/tcd-8-999-2014)

Rack W, Haas C and Langhorne PJ (2013) Airborne thickness and freeboard measurements over the McMurdo Ice Shelf, Antarctica, and implications for ice density. J. Geophys. Res., 118(C11), 5899-5907 (doi: 10.1002/2013JC009084)

Reid JE and Bishop J (2004) Post-processing calibration of frequency-domain electromagnetic data for sea-ice thickness measurements. Expl. Geophys., 35(4), 283-287 (doi: 10.1071/ EG04283)

Reid JE, Worby AP, Vrbancich J and Munro AIS (2003) Shipborne electromagnetic measurements of Antarctic sea-ice thickness. Geophysics, 68(5), 1537-1546 (doi: 10.1190/1.1620627)

Reid JE, Pfaffling A, Worby AP and Bishop JR (2006) In situ measurements of the direct-current conductivity of Antarctic sea ice: implications for airborne electromagnetic sounding of seaice thickness. Ann. Glaciol., 44, 217-223 (doi: 10.3189/ 172756406781811772)

Salem HS and Chilingarian GV (1999) The cementation factor of Archie's equation for shaly sandstone reservoirs. J. Petrol. Sci. Eng., 23(2), 83-93 (doi: 10.1016/S0920-4105(99)00009-1)

Smith IJ, Langhorne PJ, Haskell TG, Trodahl HJ, Frew R and Vennell MR (2001) Platelet ice and the land-fast sea ice of McMurdo Sound, Antarctica. Ann. Glaciol., 33, 21-27 (doi: 10.3189/ 172756401781818365)

Stogryn A and Desargant GJ (1985) The dielectric properties of brine in sea ice at microwave frequencies. IEEE Trans. Antennas Propag., 33(5), 523-532 (doi: 10.1109/TAP.1985.1143610)

Won IJ, Oren A and Funak F (2003) GEM-2A: a programmable broadband helicopter-towed electromagnetic sensor. Geophysics, 68(6), 1888-1895 (doi: 10.1190/1.1635041) 